\title{
Effect of tamoxifen on ovarian reserve: A randomized controlled assessor-blind trial in a mouse model
}

\author{
Ayşe Topçu Akduman', Kemal Özerkan¹, Berrin Zik², Sabire Peker², Berrin Avcl, ${ }^{1,3}$, Barış Ata ${ }^{1,4}$ \\ 'Department of Obstetrics and Gynecology, Uludağ University Faculty of Medicine, Bursa, Turkey \\ ${ }^{2}$ Department of Histology and Embryology, Uludağ University Faculty of Veterinary Medicine, Bursa, Turkey \\ ${ }^{3}$ Department of Histology and Embryology, Uludağ University Faculty of Medicine, Bursa, Turkey \\ ${ }^{4}$ Department of Obstetrics and Gynecology, Koç University Faculty of Medicine, Istanbul, Turkey
}

\section{Abstract}

Objective: To determine whether tamoxifen (TMX) exposure causes a permanent decrease in ovarian reserve.

Material and Methods: A randomized controlled assessor-blind trial including 30 adult female inbred BALB/C mice. Fifteen mice in the TMX group were given a single 0.1 -mg dose of TMX intraperitoneally. Fifteen mice in the control group were given a single dose of the vehicle at the same volume intraperitoneally. Two cycles later, blood samples were collected for determination of anti-Müllerian hormone (AMH) levels, and the mice were sacrificed. After gonadectomy, ovarian size was measured, and follicles were counted under light microscopy.

Results: Median serum AMH levels were 6.53 and $6.14 \mathrm{ng} / \mathrm{ml}$ in the control and TMX groups, respectively ( $p=0.03$ ). Ovarian size was significantly decreased in the TMX group. While the number of primordial (9 vs 8), primary (6 vs 3), and secondary (4.5 vs 5) follicles were similar, there were significantly fewer preantral $(11.5$ vs $6, p<0.01)$ and antral $(2 \mathrm{vs} 1, \mathrm{p}: 0.03)$ follicles, as well as corpora lutea (6 vs 3 , p: 0.04$)$, in the TMX group than in the control group. The number of atretic (2.5 vs $5, \mathrm{p}: 0.048)$ follicles was increased in the TMX group.

Conclusion: Tamoxifen administration leads to arrested growth of gonadotropin-sensitive follicles, while insensitive follicles can remain unaffected. TMX is merely an endocrine disruptor, and it does not cause a decrease in primordial follicle pool. (J Turk Ger Gynecol Assoc 2014; 15: 228-32) Key words: Tamoxifen, anti-Müllerian hormone, ovarian reserve, folliculogenesis, antral follicle count

Received: 16 September, 2014

Accepted: 21 October, 2014

\section{Introduction}

The incidence of premenopausal breast cancer is 15.1 per 100,000 woman-years for white women under 40 years of age (1). As such, it is the most common malignancy among women of reproductive age (1). While surgery is the mainstay of treatment, adjuvant chemotherapy significantly improves the survival of women with breast cancer. The 15-year survival rate of breast cancer patients under age 40 is increased by $6.1 \%$ if they receive chemotherapy (2).

However, chemotherapy can be gonadotoxic and impair the reproductive potential of women who survive the disease. The extent of gonadal damage inflicted by chemotherapy depends on several factors, including the age and pre-treatment ovarian reserve status of the patient, as well as the type, dose, and duration of the chemotherapy regimen.

Tamoxifen (TMX) is one of the commonly used agents for adjuvant chemotherapy following breast cancer. Compared to placebo, TMX results in a $13 \%$ and $15 \%$ reduction in the risk of recurrence and breast cancer mortality, respectively (3). While the gonadotoxicity of some chemotherapeutics, such as alkylating agents, is well established, there is limited information regarding whether TMX is harmful to the ovaries.

In the present study, we evaluated ovarian reserve, as assessed by serum anti-Müllerian hormone (AMH) levels and follicle counts, before and after TMX administration in a mouse model.

\section{Material and Methods}

The study protocol was in accordance with the National Institute of Health Guide for the Care and Use of Laboratory Animals and was approved by the Animal Care Committee of Uludağ University (no: 2012-04/08) (4).

\footnotetext{
Animals and experimental protocol

Thirty 8-week-old female inbred BALB/C mice weighing 25-30 g were housed in ambient temperature of $20-24^{\circ} \mathrm{C}$ and humidity of $60 \%-70 \%$. The lab had a 12 -h light and dark cycle. Mice had access to chow and water ad libitum.
} 
The mice were randomly allocated to two groups. Fifteen mice in the TMX group were given a single 0.1 -mg dose of TMX (100 $\mu \mathrm{L}$ TMX in vehicle consisting of $10 \%$ ethanol and $90 \%$ corn oil) with an intraperitoneal injection. Fifteen mice in the control group were given a single dose of the vehicle at the same volume intraperitoneally.

Mice were sacrificed by ether inhalation after two estrus cycles. Ovaries were removed and fixed in Bouin's solution for 3-4 hours and embedded in paraffin blocks. Blood samples were collected by intracardiac catheterization following anesthesia. Blood samples were immediately centrifuged at $3000 \mathrm{r} / \mathrm{min}$ for 30 minutes at room temperature, and the supernatant was collected for cryostorage at $-20^{\circ} \mathrm{C}$ until analysis.

\section{Follicle counts}

Paraffin-embedded ovarian tissues were sectioned at 4-5 $\mu \mathrm{m}$. The largest cross-section was used for Crossmann's triple staining in order to count the follicles in each developmental stage under light microscopy (5). The surface area of this section was measured in order to give a surrogate measure for ovarian size. A digital camera (Sony DSC-F717, Tokyo, Japan) attached to a Nikon 4S-2 Alphaphot light microscope (Nikon 4S-2 Alphaphot, Tokyo, Japan) and Scion-Image software (Scion Corporation, Boonsboro, Maryland, U.S.) were used for the measurements. The image analysis system was calibrated using a stage micrometer.

The follicles were categorized as follows: primordial, an oocyte surrounded by squamous pre-granulosa cells, of which not more than one is an enlarged granulosa cell; primary, a relatively larger oocyte surrounded by at least two or more cuboidal granulosa cells; secondary (transitional), an oocyte surrounded by two to three layers of cuboidal granulosa cells; pre-antral, an oocyte surrounded by more than three layers of granulosa cells with no apparent antrum; antral, an oocyte surrounded by multiple layers of granulosa cells with an antrum; and atretic, an oocyte with a pyknotic nucleus and vacuolated cytoplasm and detached granulosa cells also showing degenerative changes and floating freely in the antrum (Figure 1) (6).

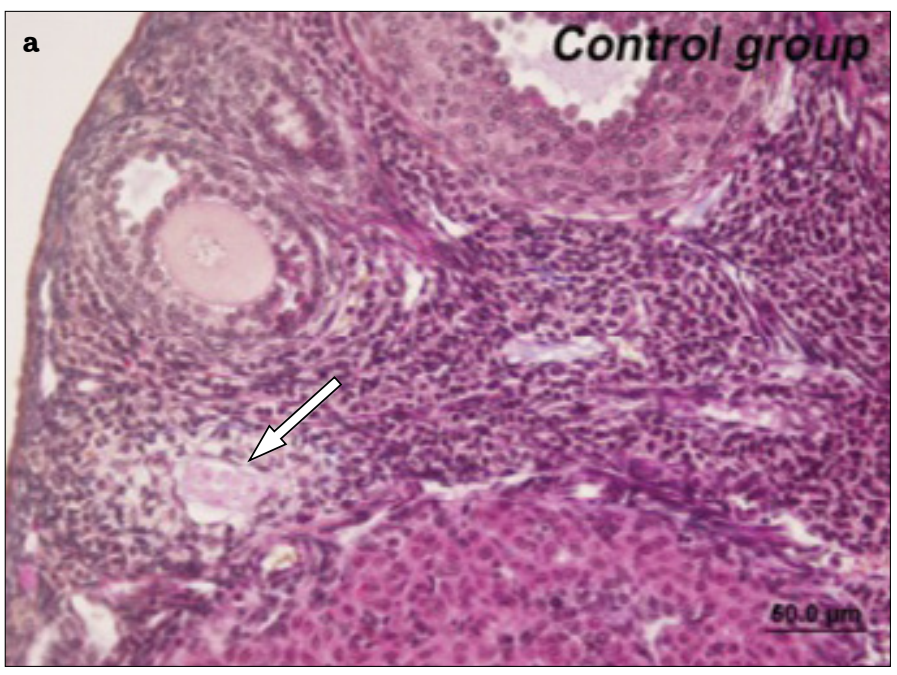

\section{AMH measurements}

A mouse AMH kit (Hangzhou Eastbiopharm Co. Ltd.; Hangzhoui, China) was used to determine plasma AMH levels using the ELISA method. The analytical sensitivity of the kit was $0.05 \mathrm{ng} /$ $\mathrm{mL}$, and the boundaries of analysis were $0.1-40 \mathrm{ng} / \mathrm{mL}$.

\section{Statistical analysis}

Continuous variables were defined with median and interquartile ranges. Mann-Whitney U-test was used for comparisons between the study groups. A two-sided $\mathrm{p}$ value $<0.05$ was considered statistically significant. Statistical Package for Social Sciences v20 (IBM; Armonk, N.Y., U.S.A.) was used for analyses.

\section{Results}

While 25 mice survived during the study period, 5 mice in the control group were found dead in their cages 4 days after intraperitoneal injection. Upon laparotomy, there was no evidence of peritonitis or bowel perforation, and the cause of death remained unknown for these mice. They are not included in the comparative analysis.

\section{Area of ovarian section}

The largest cross-section of the ovaries was significantly smaller in TMX-exposed mice than in the controls $\left(1.51,1.09-1.84 \mathrm{~mm}^{2}\right.$ vs $2.12,1.63-2.62 \mathrm{~mm}^{2}$, respectively, $\mathrm{p}=0.01$ ).

\section{Follicle counts}

Follicles of all stages were observed in ovarian sections of both the control and TMX groups (Figure 2).

While the numbers of primordial, primary, and secondary follicles were similar in the two groups, there were significantly fewer preantral and antral follicles and corpora lutea present in the TMX group than in the control group. The number of atretic follicles was increased in the TMX group. The follicle counts in both groups are presented in Table 1 .

\section{Plasma levels of AMH}

Median serum AMH levels were 6.53 (5.71-7.47) and 6.14 (6.06$6.52) \mathrm{ng} / \mathrm{mL}$ in the control and TMX groups, respectively $(\mathrm{p}=0.03)$.

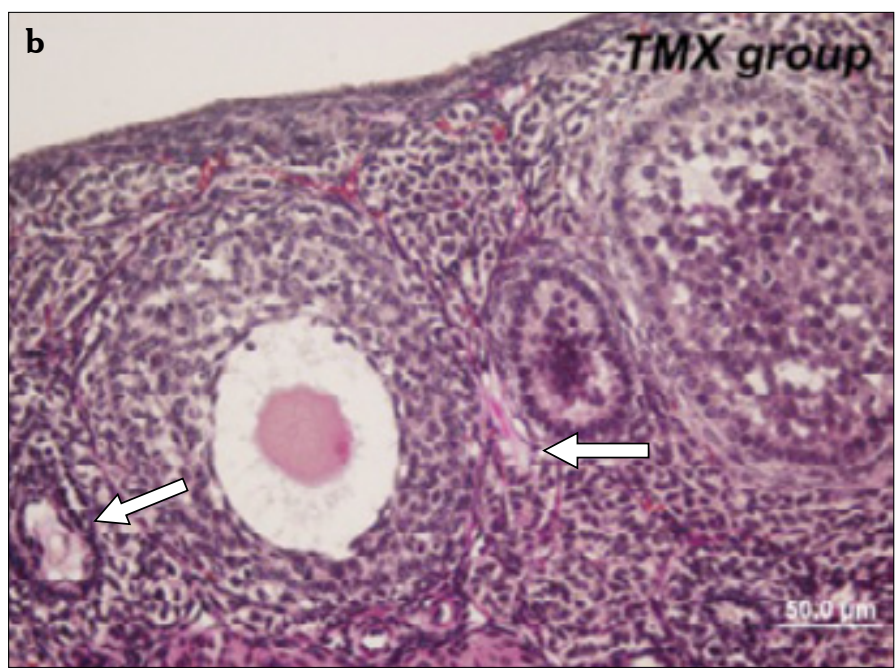

Figure 1. a, b. Ovarian sections of control (a) and tamoxifen-exposed (b) mice show atretic follicles. Arrows indicate atretic follicles 

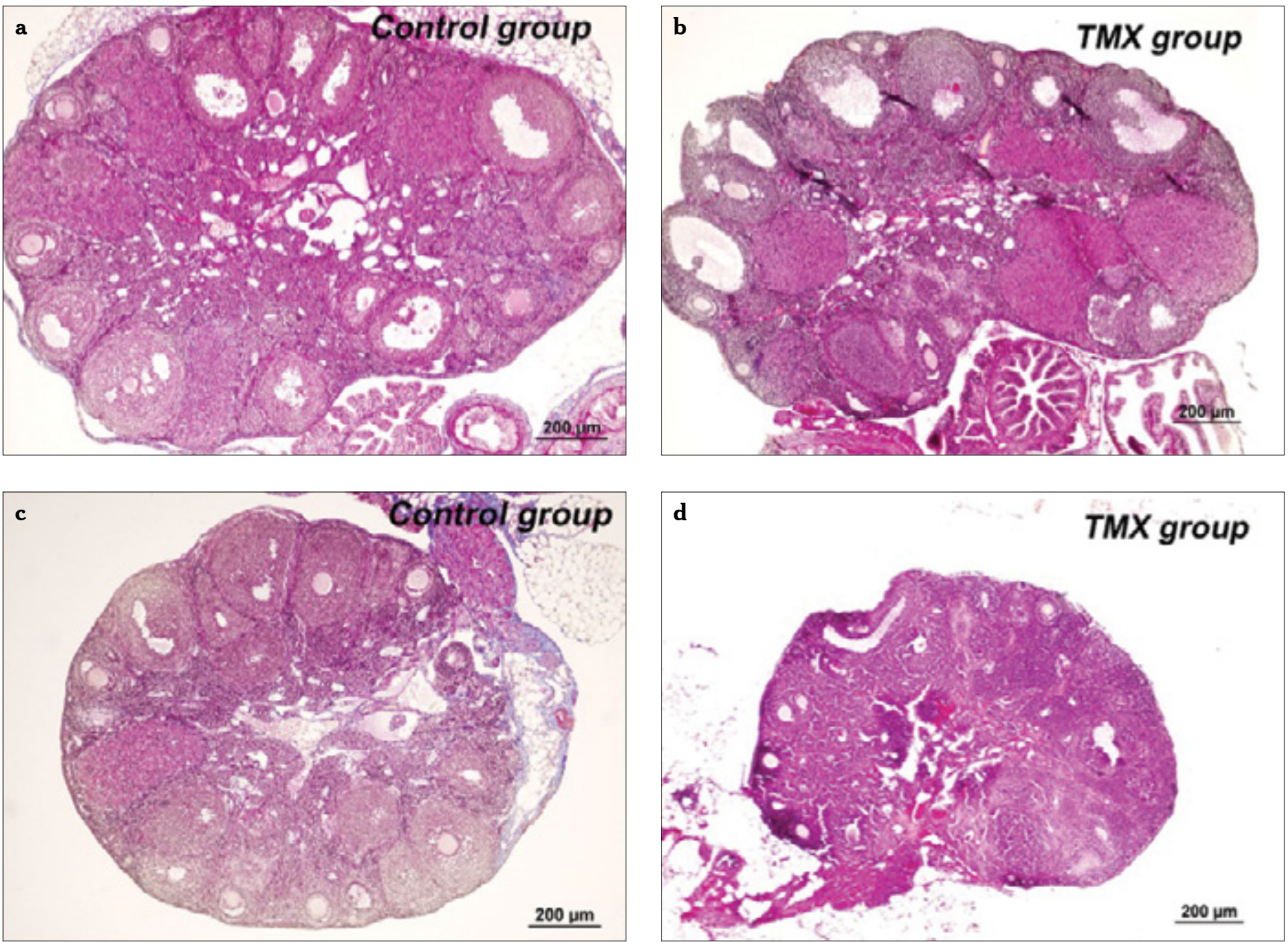

Figure 2. a-d. Ovarian sections of control (a,c) and tamoxifen-exposed (b,d) mice show follicles in different stages of development. Ovarian size is reduced in tamoxifen-exposed mice

Table 1. Follicle counts in ovarian specimens from tamoxifen and control groups

\begin{tabular}{|l|c|c|c|}
\hline Follicle type & $\begin{array}{c}\text { Control } \\
(\mathbf{n}=10)\end{array}$ & $\begin{array}{c}\text { Tamoxifen } \\
(\mathbf{n}=15)\end{array}$ & p value \\
\hline Primordial & $9(6-11)$ & $8(6-13)$ & 0.89 \\
\hline Primary & $6(3-7)$ & $3(3-5)$ & 0.26 \\
\hline Secondary & $4.5(2.8-7.8)$ & $5(4-6)$ & 0.68 \\
\hline Preantral & $11.5(9-16.3)$ & $6(4-9)$ & $<0.01$ \\
\hline Antral & $2(0.8-2)$ & $1(1-1)$ & 0.03 \\
\hline Corpora lutea & $6(2-8)$ & $3(1-5)$ & 0.04 \\
\hline Atretic & $2.5(1.5-4.5)$ & $5(4-7)$ & 0.048 \\
\hline \multicolumn{4}{|l|}{ All values are median $\left(25^{\text {th-75 }}\right.$ percentile). } \\
\hline
\end{tabular}

\section{Discussion}

Our results indicate that TMX exposure is associated with decreased ovarian size and decreased numbers of pre-antral and antral follicles in ovarian sections. However, the numbers of primordial, primary, and secondary follicles were not affected. In addition, while the number of corpora lutea decreased, the number of atretic follicles increased following TMX exposure. Finally, TMX was also associated with a significant decrease in serum AMH levels, a finding that is in keeping with the observed decrease in pre-antral and antral follicle counts, the major source of circulating $\mathrm{AMH}$.

Tamoxifen is a selective estrogen receptor modulator; however, its mechanism of action in different tissues is not clearly understood. Upon binding to nuclear estrogen receptors, TMX causes a conformational change of the dimeric receptor and interferes with its interactions with co-factors of estrogen receptormediated gene regulation. The type of estrogen receptor, such as ER-alpha or ER-beta, and variations in co-factors in different tissues and under different conditions are likely to play a role in the tissue-specific effects of TMX. While TMX blocks the effects of endogenous estrogen in breast tissue, it exerts estrogenic effects in the uterus, bone, and liver. It is thought to interfere with estrogen feedback at the hypothalamic and pituitary levels. However, there are limited data about the direct effects on the ovary and ovarian follicles. 
The effects of TMX on various organ systems, the estrous cycle, and fertility potential were investigated in a number of rodent studies (7-11). In these studies, TMX was administered orally (7, 9-11) or subcutaneously (8) for 2 to 4 weeks. The daily TMX dose ranged between 0.03 and $5 \mathrm{mg} / \mathrm{kg}$. TMX exposure led to anovulation in the majority of rats in all but one study assessing estrous cycles-70\% of TMX-exposed rats were anovulatory in the study by Donath and Nishino $(8,9,11)$.

Compared to controls, both absolute and relative ovarian weight was found to be significantly decreased following TMX exposure in all but one study (7-11). Similar to our findings, Matsuda et al. (7) and Tsujioka et al. (11) noted a decrease in the number and size of corpora lutea in TMX-treated groups. Tsujioka et al. (11) reported similar numbers of small- and medium-sized follicles in TMX-treated and control groups, which was consistent with our observations. In addition to follicle counts under light microscopy, Tsujioka et al. (11) conducted immunohistochemical staining with anti-proliferating cell nuclear antigen (PCNA) antibody in order to better identify resting primordial follicles. PCNA immune-stained sections confirmed the similar numbers of small- and medium-sized follicles in TMX and control groups. Unchanged numbers of small follicles, which represent gonadotropin-insensitive primordial and primary follicles, accompanied by decreased numbers of pre-antral and antral follicles, as well as decreased numbers of corpora lutea, were observations that were common to all of the studies mentioned above (7-11). This suggests that TMX per se is not harmful for resting primordial and gonadotropin-insensitive small follicles. However, the decreased numbers of pre-antral and antral follicles and corpora lutea, accompanied by increased numbers of atretic follicles, suggest that gonadotropin stimulation of further follicular growth and ovulation is impaired with prolonged TMX exposure. This is also supported by the observation of impaired estrous cycles in the studies by Donath (8) and Tsujioka (11). In the only study in which serum gonadotropin levels were assessed, basal levels of serum luteinizing hormone, androgens, and estradiol were found to be decreased in TMX-treated rats. Preovulatory surges of $\mathrm{LH}$ and follicle-stimulating hormone (FSH) were also suppressed in TMX-treated rats in the same study (8). In addition, the significantly decreased pituitary weight that was observed following TMX exposure in the studies by Matsuda et al. (7) and Tsujioka et al. (11) suggested decreased gonadotropin production following extended TMX exposure.

In addition to gonadotropin deprivation, local effects of TMX on follicular estrogen receptors can contribute to follicular atresia. Although the exact mechanisms are unknown, it is widely accepted that FSH action is augmented by estradiol (12). Estradiol maximizes FSH induction of antrum formation, aromatase expression, and activity and $\mathrm{LH}$ receptor expression and LH activity (12-20). Whether extended TMX exposure only decreases gonadotropin production or also interferes with the stimulation of granulosa cells by existing FSH remains to be determined, but the latter could have contributed to our observations.

Overall, TMX seems to decrease gonadotropin stimulation of pre-antral and antral follicles, leading to anovulation and follicular atresia. Decreased numbers of these large follicles can lead to decreased ovarian size/weight, as observed in the present and former studies. As pre-antral and early antral follicles produce $\mathrm{AMH}$, the decreased serum $\mathrm{AMH}$ levels observed in our study are consistent with histological observations. However, the preserved numbers of primordial, primary, and secondary follicles suggest that the resting follicle pool is unaffected by extended TMX exposure. Therefore, despite impaired growth of gonadotropin-sensitive/-dependent pre-antral and antral follicles, it is reasonable to suggest that ovarian reserve, defined as the quantity of resting follicles, remains unaffected by TMX exposure. TMX seems to be solely an endocrine disruptor, and ovaries should be able to respond adequately to gonadotropin stimulation following restoration of hypothalamo-pituitary-ovarian feedback mechanisms.

Ethics Committee Approval: Ethics committee approval was received for this study from Animal Care Committee of Uludağ University.

Informed Consent: N/A.

Peer-review: Externally peer-reviewed.

Author contributions: Concept - K.Ö.; Design - K.Ö., A.T.A.; Supervision - K.Ö., B.Ata.; Resource - K.Ö., A.T.A.; Materials - A.T.A., B.Z. ; Data Collection\&/or Processing - A.T.A., B.Z., S.P., B.Avcı.; Analysis\&/or Interpretation - B.Ata, K.Ö., A.T.A.; Literature Search - B.Ata., A.T.A.; Writing - B.Ata., A.T.A.; Critical Reviews - K.Ö., B.Avcı., B.Z.

Conflict of Interest: No conflict of interest was declared by the authors.

Financial Disclosure: The authors declared that this study has received no financial support.

\section{References}

1. Brinton LA, Sherman ME, Carreon JD, Anderson WF. Recent trends in breast cancer among younger women in the United States. J Natl Cancer Inst 2008; 100: 1643-8. [CrossRef]

2. Early Breast Cancer Trialists' Collaborative G. Effects of chemotherapy and hormonal therapy for early breast cancer on recurrence and 15-year survival: An overview of the randomised trials. Lancet 2005; 365: 1687-717. [CrossRef]

3. Dowsett M, Cuzick J, Ingle J, Coates A, Forbes J, Bliss J, et al. Meta-analysis of breast cancer outcomes in adjuvant trials of aromatase inhibitors versus tamoxifen. J Clin Oncol 2010; 28: 509-18. 4. National Research Council (US) Committee for the Update of the Guide for the Care and Use of Laboratory Animals. Guide for the Care and Use of Laboratory Animals. 8th ed. Washington D.C.: National Academic Press; 2011.

5. Parrott JA, Skinner MK. Kit-ligand/stem cell factor induces primordial follicle development and initiates folliculogenesis. Endocrinology 1999; 140: 4262-71.

6. Oktay K, Schenken RS, Nelson JF. Proliferating cell nuclear antigen marks the initiation of follicular growth in the rat. Biol Reprod 1995; 53: 295-301. [CrossRef]

7. Matsuda A, Higuchi K, Karasawa M, Yoneyama S, Deguchi J, Miyamoto M. Fourteen-day oral combination dose toxicity study of CGS 16949 A (aromatase inhibitor) with 5-fluorouracil or tamoxifen in rats. J Toxicol Sci 1997; 22: 1-24. [CrossRef]

8. Donath J, Nishino Y. Effects of partial versus pure antiestrogens on ovulation and the pituitary-ovarian axis in the rat. J Steroid Biochem Mol Biol 1998; 66: 247-54. [CrossRef]

9. Cho SD, Kim JH, Kim DY, Lee YS, Kang KS. Pre-validation study for OECD enhanced test guideline 407 protocol by gavage for 4 weeks 
using propylthiouracil and tamoxifen. Toxicol Lett 2003; 144: 195204. [CrossRef]

10. Kennel P, Pallen C, Barale-Thomas E, Espuna G, Bars R. Tamoxifen: 28-day oral toxicity study in the rat based on the Enhanced OECD Test Guideline 407 to detect endocrine effects. Arch Toxicol 2003; 77: 487-99. [CrossRef]

11. Tsujioka S, Ban Y, Wise LD, Tsuchiya T, Sato T, Matsue K, et al. Collaborative work on evaluation of ovarian toxicity. 3) Effects of 2- or 4- week repeated-dose toxicity and fertility studies with tamoxifen in female rats. J Toxicol Sci 2009; (34 Suppl 1): SP43-51.

12. Couse JF, Yates MM, Deroo BJ, Korach KS. Estrogen receptor-beta is critical to granulosa cell differentiation and the ovulatory response to gonadotropins. Endocrinology 2005; 146: 3247-62. [CrossRef]

13. Fitzpatrick SL, Richards JS. Regulation of cytochrome P450 aromatase messenger ribonucleic acid and activity by steroids and gonadotropins in rat granulosa cells. Endocrinology 1991; 129: 1452-62. [CrossRef]

14. Zhuang LZ, Adashi EY, Hsuch AJ. Direct enhancement of gonadotropin-stimulated ovarian estrogen biosynthesis by estrogen and clomiphene citrate. Endocrinology 1982; 110: 2219-21. [CrossRef]
15. Adashi EY, Hsueh AJ. Estrogens augment the stimulation of ovarian aromatase activity by follicle-stimulating hormone in cultured rat granulosa cells. J Biol Chem 1982; 257: 6077-83.

16. Segaloff DL, Wang HY, Richards JS. Hormonal regulation of luteinizing hormone/chorionic gonadotropin receptor mRNA in rat ovarian cells during follicular development and luteinization. Molecular endocrinology. 1990; 4: 1856-65. [CrossRef]

17. Kessel B, Liu YX, Jia XC, Hsueh AJ. Autocrine role of estrogens in the augmentation of luteinizing hormone receptor formation in cultured rat granulosa cells. Biol Reprod 1985; 32: 1038-50. [CrossRef]

18. Knecht M, Darbon JM, Ranta T, Baukal AJ, Catt KJ. Estrogens enhance the adenosine 3',5'-monophosphate-mediated induction of follicle-stimulating hormone and luteinizing hormone receptors in rat granulosa cells. Endocrinology 1984; 115: 41-9. [CrossRef]

19. Knecht M, Brodie AM, Catt KJ. Aromatase inhibitors prevent granulosa cell differentiation: an obligatory role for estrogens in luteinizing hormone receptor expression. Endocrinology 1985; 117: 1156-61. [CrossRef]

20. Goldenberg RL, Vaitukaitis JL, Ross GT. Estrogen and follicle stimulation hormone interactions on follicle growth in rats. Endocrinology 1972; 90: 1492-8. [CrossRef] 